\title{
ANALISIS PENGETAHUAN IBU NIFAS TENTANG TANDA BAHAYA MASA NIFAS TERHADAP PEMANFAATAN BUKU KIA DI RSU BUDI KEMULIAAN
}

\section{ANALYSIS OF KNOWLEDGE OF POSTPARTUM MOTHERS ABOUT ALERT SIGNS OF POSTPARTUM PERIOD TOWARDS THE USE OF MATERNAL AND CHILD'S HEALTH BOOKS AT BUDI KEMULIAAN GENERAL HOSPITAL}

\author{
Sri Hartini Rahayu, Anik Rosita \\ Sekolah Tinggi Ilmu Kesehatan Budi Kemuliaan \\ Korespondensi : sri.hartini235@gmail.com
}

\begin{abstract}
Postpartum period is a time of risk of complications for the mother, because the reproductive organs in the process of recovery. Families and post partum women are not aware of itbecause the focus of their attention is on the newborn. Post partum support is needed for a mother so that childbirth can be passed without complication. Family and postpartum mothers' knowledge about the alert signs in the use of the MCH Handbook is needed so that postpartum mothers and their families can immediately come to health facilities if they experience alert signs during the postpartum period. Research purposes was to analyze of knowledge of postpartum mothers about alert signs postpartum towards the use of maternal and child's health book at Budi Kemuliaan General Hospital in the period of May-June 2019. The research method used analytical survey with a cross sectional study design. The research sample consisted of 110 postpartum mothers. Conclusion, can be donated. Using the of mother and child's health book at Budi Kemuliaan Hospital In 2019 respondents used of maternal and child's health books and had good knowledge.
\end{abstract}

Keywords: maternal and child's health books, alert signs of postpartum

\begin{abstract}
ABSTRAK
Masa nifas merupakan masa yang berisiko terjadinya komplikasi bagi ibu , karena alat reproduksi dalam proses pemulihan. Keluarga dan ibu nifas tidak menyadari hal tersebut karena focus perhatian mereka tertuju pada bayi baru lahir. Dukungan masa nifas sangat dibutuhkan bagi seorang ibu supaya masa nifas dapat dilalui tanpa komplikasi. Pengetahuan keluarga dan ibu nifas tentang tanda - tanda bahaya dalam pemanfaatan buku KIA sangat diperlukan agar ibu nifas dan keluarga dapat segera datang ke fasilitas kesehatan apabila mengalami tanda bahaya dalam masa nifas. Tujuan penelitian untuk menganalisis Pengetahuan Ibu nifas tentang tanda-tanda bahaya masa nifas Dalam Pemanfaatan Buku KIA di Ruang Srikandi RSU Budi Kemuliaan Periode Mei- Juni 2019. Metode Penelitian ini adalah menggunakan penelitian analitik dengan desain cross sectional Sampel penelitian sebanyak 110 orang ibu nifas. Pengumpulan data menggunakan kuesioner serta menggunakan analisis univariat dan bivariat yang diolah menggunakan sistem computer. Hasil penelitian sebagian besar Pengetahuan Ibu Dalam Pemanfaatan Buku KIA diruang Srikandi RSU Budi Kemuliaan Periode Mei-Juni 2019, memiliki pengetahuan yang baik.
\end{abstract}

Kata Kunci: Pemanfaatan Buku KIA, Tanda Bahaya Ibu Nifas 


\section{PENDAHULUAN}

Kematian dan kesakitan ibu masih merupakan masalah kesehatan yang serius di Negara berkembang. Menurut laporan World Health Organization (WHO) tahun 2014 Angka Kematian Ibu (AKI) di dunia yaitu 289.000 jiwa. Beberapa Negara memiliki AKI cukup tinggi seperti Afrika Sub-Saharan 179.000 jiwa. Asia Selatan 69.000 jiwa, dan Asia Tenggara 16.000 jiwa. Angka kematian ibu di Negara-negara Asia Tenggara yaitu Indonesia 190 per 100.000 kelahiran hidup, Vietnam 49 per 100.000 kelahiran hidup, Thailand 26 per 100.000 kelahiran hidup, Brunei 27 per 100.000 kelahiran hidup, dan Malaysia 29 per 100.000 kelahiran (WHO,2014).

Menurut laporan dari WHO, kematian ibu umumnya terjadi akibat komplikasi saat, dan pasca kehamilan.Adapun jenisjenis komplikasi yang menyebabkan mayoritas kasus kematian ibu - sekitar $75 \%$ dari total kasus kematian ibu adalah pendarahan, infeksi, tekanan darah tinggi saat kehamilan, komplikasi persalinan, dan aborsi yang tidak aman (WHO, 2014). Untuk kasus Indonesia sendiri, berdasarkan data dari Pusat Kesehatan dan Informasi Kemenkes (2014) penyebab utama kematian ibu dari tahun 2010-2013 adalah pendarahan (30.3\% pada tahun 2013) dan hipertensi (27.1\% pada tahun 2013). Hal ini sangat ironis,mengingat berbagai penyebab kematian ibu di atas sebenarnya dapat dicegah, jika ibu hamil mendapatkan perawatan medis yang tepat.

Masa nifas merupakan masa yang rentan bagi kelangsungan hidup ibu baru bersalin. Menurut Studi Tindak Lanjut Kematian Ibu SP 2010 ( Afiffah dkk, 2011), sebagian besar kematian ibu terjadi pada masa nifas sehingga pelayanan kesehatan masa nifas berperan penting dalam upaya menurunkan angka kematian ibu. .

Tujuan penelitian untuk menganalisis Pengetahuan Ibu nifas tentang tanda-tanda bahaya masa nifas Dalam Pemanfaatan Buku KIA di Ruang Srikandi RSU Budi Kemuliaan.

\section{METODE}

Desain penelitian yang digunakan dalam penelitian ini adalah "cross sectional yaitu untukmenganilisis pengetahuan ibu nifas tentang tanda - tanda bahaya ibu nifas dalam pemantauan buku KIA Dengan demikian data pengukuran yang menyangkut variabel bebas dan terkait di lakukan pada waktu yang bersama menggunakan data primer melalui kuesioner. Populasi dalam penelitian ini adalah ibu nifas di RSU Budi Kemuliaan., jumlah sampel bersadaskan rumus Solvin yaitu : 110 orang. Dengan memenuhi kliteria sebagai berikut : 
a. Kriteria inklusi :

ibu nifas yang di rawat di Ruang Srikandi

b. Kritera eksklusi :

Ibu nifas yang mengundurkan diri menjadi responden

Hasil pengumpulan data diolah dan dianalisis melalui proses pengolahan yang meliputi editing, entry, tabulasi menggunakan Microsoft word dan spss. Penelitian ini dianalisis dengan menggunakan analisis univariat dan bivariat menggunakan uji “ kolerasi Rank spearman“. Dinilai dengan nilai $\mathrm{p}$, jika pvalue $\leq 0,05$, berarti ada hubungan yang bermakna, dan jika $\mathrm{p}>0,05$, berarti tidak ada hubungan yang bermakna.

Analisis Univariat

Dilakukan secara deskritif dalam menggambarkan variabel penelitian. Variabel kategorik akan melihat distribusi frekuensi atau presentasi. Untuk mengetahui kemampuan ibu mengenai tanda-tanda bahaya nifas digunakan perhitungan sebagai berikut :

1. $\geq 75 \%$ jawaban benar= Baik

2. $56-74 \%$ jawaban benar= Cukup

3. $\leq 55$ jawaban benar $=$ Kurang

Analisis Bivariat

Analisis Bivariat adalah tabel silang antara dua variabel yaitu variabel dependen dan variabel independen. Analisis ini dilakukan untuk melihat ada tidaknya hubungan variabel independen dan dependen. Dapat digunakan dengan uji chi square

\section{HASIL DAN PEMBAHASAN}

Tabel.1 Distribusi responden menurut karakteristik responden

\begin{tabular}{lcc}
\hline $\begin{array}{l}\text { Karakteristik } \\
\text { Responden }\end{array}$ & $\mathbf{N}$ & $\mathbf{\%}$ \\
\hline 1. Umur & & \\
\hline$<20$ tahun & 3 & 2.72 \\
\hline $20-35$ tahun & 89 & 80.90 \\
\hline$>35$ tahun & 18 & 16.36 \\
\hline Total & 110 & 100 \\
\hline
\end{tabular}

\section{Pendidikan}

\begin{tabular}{lcc}
\hline SD & 10 & 9.09 \\
\hline SMP & 19 & 17.27 \\
\hline SMA & 64 & 58.18 \\
\hline PT & 17 & 15.45 \\
\hline Total & 110 & 100 \\
\hline
\end{tabular}

3. Pekerjaan

\begin{tabular}{lcc}
\hline IRT & 78 & 70.90 \\
\hline Swasta & 24 & 21.81 \\
\hline Wirausaha & 7 & 6.36 \\
\hline PNS & 1 & 0.90 \\
\hline Total & 110 & 100 \\
\hline
\end{tabular}

4. Paritas

\begin{tabular}{lcc}
\hline Primipara & 36 & 32.72 \\
\hline Multipara & 43 & 39.09 \\
\hline Grandemultipara & 31 & 28.18 \\
\hline Total & 110 & 100 \\
\hline
\end{tabular}

5. Sumber Informasi

\begin{tabular}{lcc}
\hline Tenaga kesehatan & 91 & 82.72 \\
\hline media cetak & 3 & 2.72 \\
\hline media elektronik & 2 & 1.81 \\
\hline media social & 14 & 12.72 \\
\hline Total & 110 & 100 \\
\hline
\end{tabular}

6. Pengetahuan

\begin{tabular}{lcc}
\hline Baik & 42 & 38.18 \\
\hline Cukup & 41 & 37.27 \\
\hline Kurang & 27 & 24.54 \\
\hline Total & 110 & 100 \\
\hline
\end{tabular}


Tabel 2. Distribusi Umur Ibu Berdasarkan Kategori Pengetahuan

\begin{tabular}{|c|c|c|c|c|c|c|c|}
\hline \multirow[t]{3}{*}{ Variabel } & \multicolumn{6}{|c|}{ Pengetahuan } & \multirow{3}{*}{$\begin{array}{l}\text { Nilai } \\
P\end{array}$} \\
\hline & \multicolumn{2}{|l|}{ Baik } & \multicolumn{2}{|c|}{ Cukup } & \multicolumn{2}{|c|}{ Kurang } & \\
\hline & $\mathbf{F}$ & $\%$ & $\mathbf{F}$ & $\%$ & $\mathbf{F}$ & $\%$ & \\
\hline \multicolumn{8}{|l|}{ Umur Ibu } \\
\hline$<20$ th & 0 & 0 & 2 & 1,8 & 1 & 0,9 & \multirow{4}{*}{0,675} \\
\hline $21-35$ th & 36 & 32,7 & 32 & 29,1 & 21 & 19,1 & \\
\hline$>35$ th & 6 & 5,5 & 7 & 6,4 & 5 & 4,5 & \\
\hline Jumlah & 42 & 38,2 & 41 & 37,3 & 27 & 24,5 & \\
\hline \multicolumn{8}{|l|}{ Pendidikan } \\
\hline SD & 4 & 3,6 & 3 & 2,7 & 3 & 2,7 & \multirow{5}{*}{0,655} \\
\hline SMP & 8 & 7,3 & 5 & 4,5 & 6 & 5,5 & \\
\hline SMA & 21 & 19,1 & 28 & 25,5 & 15 & 13,6 & \\
\hline PT & 9 & 8,2 & 5 & 4,5 & 3 & 2,7 & \\
\hline Jumlah & 42 & 38,2 & 41 & 37,3 & 27 & 24,5 & \\
\hline \multicolumn{8}{|l|}{ Pekerjaan } \\
\hline IRT & 34 & 30,9 & 25 & 22,7 & 19 & 17,3 & \multirow{5}{*}{0,080} \\
\hline Swasta & 7 & 6,4 & 9 & 8,2 & 8 & 7,3 & \\
\hline Wirausaha & 1 & 0,9 & 6 & 5,5 & 0 & 0 & \\
\hline PNS & 0 & 0 & 1 & 0,9 & 0 & 0 & \\
\hline Jumlah & 42 & 38,2 & 41 & 37,3 & 27 & 24,5 & \\
\hline \multicolumn{8}{|l|}{$\begin{array}{l}\text { Sumber } \\
\text { Informasi }\end{array}$} \\
\hline Nakes & 36 & 32,7 & 35 & 31,8 & 20 & 18,2 & \multirow{5}{*}{0,496} \\
\hline Media Cetak & 2 & 1,8 & 0 & 0 & 1 & 0,9 & \\
\hline $\begin{array}{l}\text { Media } \\
\text { Elektronik }\end{array}$ & 1 & 0,9 & 0 & 0 & 1 & 0,9 & \\
\hline Media Sosial & 3 & 2,7 & 6 & 5,5 & 5 & 4,5 & \\
\hline Jumlah & 42 & 38,2 & 41 & 37,3 & 27 & 24,4 & \\
\hline
\end{tabular}

Berdasarkan tabel 2 menunjukkan bahwa hubungan usia ibu nifas dengan tingkat pengetahun ibu tentang tanda - tanda bahaya ibu nifas dalam pemanfaatan buku KIA menunjukkan bahwa secara satatistik tidak ada hubungan yang bermakna antara usia dengan tingkat pengetahuan ibu nifas tentang tanda bahaya ibu nifas dalam buku KIA nilai $P$ value 0,675 . Hubungan pendidikan ibu dengan tingkat pengetahuan tentang tanda - tanda bahaya ibu nifas dalam buku KIA menunjukkan bahwa secara statistik tidak ada hubungan yang bermakna antara pendidikan dan tingkat pengetahuan ibu tentang tanda bahaya ibu nifas dalam buku KIA nilai P value 0,655.

Hubungan pekerjaan ibu dengan tingkat pengetahuan tentang tanda - tanda bahaya ibu nifas dalam buku KIA menunjukkan bahwa secara statistik tidak ada hubungan yang bermakna antara pekerjaan dan tingkat pengetahuan ibu tentang tanda bahaya ibu nifas dalam buku KIA nilai $\mathrm{P}$ value 0,080 . Hubungan pendidikan ibu dengan tingkat pengetahuan tentang tanda - tanda bahaya ibu nifas dalam buku KIA menunjukkan bahwa secara statistik tidak ada hubungan yang bermakna antara sumber informasi dengan tingkat pengetahuan ibu tentang tanda bahaya ibu nifas dalam buku KIA nilai $\mathrm{P}$ value 0,496 .

Berdasarkasn usia ibu nifas menunjukkan bahwa masih terdapat 19,08 $\%$ ibu bersalin yang berisiko tinggi yaitu pada usia $<20$ tahun $>35$ tahun, konseling pra konsepsi sangat diperlukan agar pasangan suami istri dapat merencanakan kehamilannya dengan sebaik baiknya, agar dapat menjalani masa kehamilan, persalinan dan nifas dengan baik.

Berdasarkan pendidikan responden masih terdapat 9, 09\% berpendidikan SD. Pendidikan merupakan proses tumbuh kembang seluruh kemampuan dan perilaku manusia melalui pengajaran . Tingkat 
pendidikan merupakan salah satu faktor yang mempengaruhi persepsi seseorang untuk lebih menerima ide - ide dan teknologi. yang baru, Semakin tinggi tingkat pendidikan seseorang, maka akan bertambah pengalaman yang mempengaruhi wawasan dan pengetahuan. Berdasarkan pekerjaan responden didapatkan hasil analisis yang paling banyak yaitu ibu rumah tangga dengan persentase $(70,90 \%)$, dan yang paling sedikit bekerja sebagai PNS dengan persentase $(0,90 \%)$.

Berdasarkan paritas responden grande multi para relative masih tinggi $28,18 \%$, grande muli para sangat berisiko terjadi perdarahan post partum karena otot uterus lebih sering meregang, sehingga dindingnya menipis dan kontraksi uterus lebih lemah, untuk itu diperlukan peran tenaga kesehatan dalam konseling usia kehamilan, persalinan dan nifas yang sehat (Cunningham , 2010).

Berdasarkan sumber informasi yang didapat responden terlihat bahwa sebagian besar responden mendapat infornasi tanda - tanda bahaya ibu nifas dari tenaga kesehatan 82,72 \%,. Peran petugas kesehatan sudah sangat baik dalam sosialisasi tanda - tanda bahaya ibu nifas dalam buku KIA, namun perlu ada peningkatan agar mencapai hasil yang optimal

Berdasarkan hasil analisis diketahui bahwa hasil distribusi gambaran pengetahuan ibu nifas tentang tanda tanda bahaya masa nifas dalam pemanfaatan buku KIA di lantai 1 ruang Srikandi RSU Budi Kemuliaan antara pengetahuan yang baik tidak terlalu jauh perbedaannya, pengetahuan baik $38,18 \%$, sementara pengetahuan cukup 37,27\%,,namun masih didapatkan pengetahuan kurang $24,54 \%$, sehingga petugas kesehatan dalam hal ini bidan maupun dokter dapat meningkatkan pemberian edukasi tanda - tanda bahaya pada ibu nifas dengan pemanfaatkan buku KIA

Berdasarkan tabel 2 menunjukkan bahwa hubungan usia ibu nifas dengan tingkat pengetahun ibu tentang tanda tanda bahaya ibu nifas dalam pemanfaatan buku KIA menunjukkan bahwa secara satatistik tidak ada hubungan yang bermakna antara usia dengan tingkat pengetahuan ibu nifas tentang tanda bahaya ibu nifas dalam buku KIA nilai $P$ value 0,675. Hasil analisis hubungan antara pendidikan dengan pengetahuan tentang tanda - tanda bahaya pada ibu nifas dalam pemanfaatan buku KIA menunjukkan bahwa tidak ada hubungan bermakna secara statistik ( $P$ value 0,655 ) 
Pendidikan adalah suatu usaha untuk mengembangkan kepribadian dan kemampuan didalam dan diluar sekolah dan berlangsung seumur hidup. Pendidikan mempengaruhi proses belajar, makin tinggi pendidikan seseorang makin mudah orang tersebut untuk menerima informasi., dengan pendidikan yang tinggi maka seseorang akan cenderung untuk mendapatkan informasi, baik dari orang lain maupun dari media massa. Semakin banyak informasi yang masuk semakin banyak pula pengetahuan yang didapat tentang kesehatan. Pengetahuan erat hubungannya dengan pendidikan dimana diharapkan seseorang dengan pendidikan tinggi, maka orang tersebut akan semakin luas pula pengetahuannya. Namun perlu ditekankan bahwa seseorang yang berpendidikan rendah tidak berarti mutlak berpengetahuan rendah pula. Peningkatan pengetahuan tidak mutlak diperoleh di pendidikan formal, akan tetapi juga dapat diperoleh pada pendidikan non formal..

Berdasarkan penelitian Desi Larasati (2015) tingkat pendidikan responden yang terbesar adalah SMA yaitu sebanyak 21 responden $(63,6 \%)$. Pendidikan tersebut tergolong menengah dan sudah di atas rata-rata dengan hasil pengetahuan yang cukup baik bahwa makin tinggi pendidikan seseorang semakin mudah pula pengetahuan yang dimilikinya.

Hasil analisis hubungan antara pekerjaan dengan pengetahuan ibu nifas tentang tanda tanda bahaya masa nifas dalam pemanfaatan buku KIA menunjukkan bahwa ada hubungan yang bermakna secara statistik ( $\mathrm{P}$ value 0,080) .Pekerjaan merupakan suatu kegiatan atau aktivitas seseorang untuk memperoleh penghasilan guna memenuhi kebutuhan hidupnya sehari-hari. Pekerjaan akan mempengaruhi pengetahuan ditinjau dari jenis pekerjaan yang sering berinteraksi dengan orang lain lebih banyak pengetahuannya bila dibandingkan dengan orang tanpa ada interaksi dengan orang lain.

Hasil analisis hubungan anrata sumber informasi dengan pengetahuan ibu nifas tentang tanda - tanda bahaya masa nifas dalam pemanfaatan buku KIA menunjukkan bahwa tidak ada hubungan yang bermakna secara statistik ( $\mathrm{P}$ value $0,490)$

Informasi yang diperoleh baik dari pendidikan formal maupun non formal dapat memberikan pengaruh jangka pendek sehingga menghasilkan perubahan atau peningkatan pengetahuan. Majunya teknologi akan tersedia bermacam-macam media massa yang dapat mempengaruhi pengetahuan masyarakat tentang inovasi 
baru,. Berbagai bentuk sarana komunikasi, media massa seperti televisi, radio,surat kabar, majalah, penyuluhan dan lain-lain mempunyai pengaruh besar terhadap pembentukkan opini dan kepercayaan orang. Dalam penyampaian informasi sebagai tugas pokoknya, media massa membawa pesan-pesan yang berisi sugesti yang dapat mengarahkan opini seseorang. Adanya informasi baru mengenai sesuatu hal memberikan landasan kognitif baru bagi terbentuknya pengetahuan terhadap hal tersebut.

Dalam penelitian yang dilakukan Tiara Asyifa Sidik (2013) bahwa seseorang yang tepapar $\geq 5$ jenis media infomasi sebesar $66,1 \%$. Hasil penelitian ini menunjukkan bahwa dari berbagai macam bentuk media, media interpersonal mendapatkan pilihan terbesar sebagai sumber informasi kesehatan.

\section{SIMPULAN}

Berdasarkan hasil penelitian dapat disimpulkan bahwa:

a. Pengetahuan ibu nifas berdasarkan umur dalam distribusi pengetahuan ibu terhadap tanda-tanda bahaya pada ibu nifas di RSU Budi Kemuliaan tertinggi berdasarkan umur ibu dengan pengetahuan yang baik pada ibu berusia 20-35 tahun sebesar 40,4\%. Hal ini terjadi kemungkinan disebabkan jumlah sampel ( responden ) pada kategori usia terbanyak berusia antara 21 - 35 tahun.

b. Pengetahuan ibu nifas tentang tandatanda bahaya masa nifas berdasarkan pendidikan, tertinggi dalam kategori pengetahuan yang cukup baik pada ibu yang berpendidikan SMA sebesar $50,9 \%$. Hal ini terjadi kemungkinan disebabkan jumlah sampel ( responden ) pada kategori pendidikan terbanyak berpendidikan SMA.

c. Pengetahuan ibu nifas tentang tanda bahaya masa nifas berdasarkan pekerjaan, tertinggi dalam kategori pengetahuan yang baik pada ibu rumah tangga sebesar 43,6\%. Hal ini terjadi kemungkinan disebabkan jumlah sampel ( responden ) pada kategori pekerjaan terbanyak ibu rumah tangga

d. Pengetahuan ibu nifas berdasarkan sumber informasi di RSU Budi Kemuliaan sebagian besar sumber informasi dari tenaga kesehatan $82,72 \%$

\section{UCAPAN TERIMA KASIH}

Ucapan terima kasih diberikan kepada Bidang Penelitian Lembaga Kesehatan Budi Kemuliaan dan RSU Budi Kemuliaan dan unit rekam medik STIK Budi Kemuliaan. 
DAFTAR PUSTAKA

WHO. 2014 Maternal Mortality: World Health Organizatio.

Mubarak, 2011 Ilmu Kesehatan Masyarakat: Konsep dan Aplikasi Kebidanan. Jakarta Selatan : Salemba Medika.

Notoatmodjo, 2014.Metodologi Penelitian Kesehatan. Jakarta: Rineka Cipta.

Dinkes Provinsi Jawa Tengah. 2013. Profil Kesehatan Jawa Tengah Tahun 2012. Semarang: Dinas Provinsi Jawa Tengah. Jakarta:

Survey Demografi dan Kesehatan (SDKI). 2012. Angka Kematian Ibu. Dikutip dari www.bkkbn.co.id.

Arikunto, Suharsimi. 2006. Metode Penelitian. Yogyakarta: Binas Aksara.

Sari, E.P dan K.D. Rimandini. 2014. Asuhan Kebidanan Persalinan. Jakarta: Salemba Medika.

Sugiyono. 2017. Metode Penelitian Kuantitaif, Kualitatif, dan R\&D. Bandung: Alfabeta, CV.

Euis,L.P. 2018. Tingkat Pengetahuan Tentang Tanda-Tanda Bahaya Pada Ibu Nifas di Kamar Rawat Inap Lantai 1 RSIA Budi Kemuliaan Periode Mei 2018. 43.

Naser, Irawati, 2016, Gambaran tingkat pengetahuan ibu nifas tentang tanda bahaya masa nifas di RSUD Sleman Yogyakarta,Yogyakarta 